\title{
Effects of Seed Size and Sowing Depth on Seed Germination and Seedling Growth of Telfairia occidentalis (Hook F.)
}

\author{
Umeoka, N. and Ogbonnaya, C. I.
}

\begin{abstract}
A split plot experiment in a randomized complete block design with three replications was used to study the effect of three (small $-10 \mathrm{~g}$, medium $-22 \mathrm{~g}$, and large $-32 \mathrm{~g}$ ) seed sizes and four $(3 \mathrm{~cm}, 6 \mathrm{~cm}, 9 \mathrm{~cm}$ and $12 \mathrm{~cm})$ sowing depths on the germination and growth of Telfairia occidentalis at Uturu, Abia State, Nigeria. Small and large seeds had significantly the highest and least germination rates respectively. Small seeds gave significantly the highest leaf number plant $^{-1}$, leaf area, root length, relative growth rate and leaf,stem and root dry weights. Large seeds had statistically the least result of the above parameters. However, large seeds had the highest $(\mathrm{P} \leq 0.05)$ root-shoot ratio and leaf area ratio. Seeds sown at $3 \mathrm{~cm}$ and $6 \mathrm{~cm}$ depths germinated faster than seeds sown at $9 \mathrm{~cm}$ and $12 \mathrm{~cm}$ depths. Seeds sown at $3 \mathrm{~cm}$ depths had the highest significant percentage germination, plant heights, root shoot ratio and leaf area. However, seeds sown at $9 \mathrm{~cm}$ depth gave statistically the highest root lengths, root collar diameter and leaf diameter. In terms of plant biomass, $12 \mathrm{~cm}$ and $6 \mathrm{~cm}$ sowing depths gave significantly the highest and least leaf and stem dry weights respectively. The $9 \mathrm{~cm}$ and $12 \mathrm{~cm}$ sowing depths had higher $(\mathrm{P} \leq 0.05)$ root dry weights than the $3 \mathrm{~cm}$ and $6 \mathrm{~cm}$ sowing depths. At the $12^{\text {th }}$ week of the study $3 \mathrm{~cm}$ and $12 \mathrm{~cm}$ gave significantly the highest and least relative growth rates respectively. In terms of seed size and sowing depths treatment interactions, large seeds in all the sowing depths had the highest $(\mathrm{P} \leq 0.05)$ root shoot ratios. Small and large seeds in all the sowing depths gave significantly and respectively the highest and least relative growth rates, leaf number, root, stem and leaf dry weights. Small seeds at the various sowing depths also had significantly the highest root lengths and plant heights. This study recommends the use of small seed sizes $(10 \mathrm{~g})$ and $3 \mathrm{~cm}$ sowing depth for production of T. occidentalis.
\end{abstract}

Keywords:Effects; Seed Size and Sowing Depth; Seed Germination; Seedling Growth; Telfairiaoccidentalis.

\section{INTRODUCTION}

The effects of seed size and sowing depth on various stages of plant growth, development and establishment have been reported by many researchers. [9] reported that large seeds of sweet corn variety produced more vigorous plants and early maturity than small seeds. Large acorns of Quercus spp. produced larger seedlings than did small seeds [11]. Other researchers found the reverse as the case. [10] found out that plants with small propagules increased their weight more rapidly than the large ones in an open habitat, while in a closed habitat; large seeds did so more rapidly.

Umeoka, N. and Ogbonnaya, C. I.are with Department of Computer Usage, Adıyaman University Besni Vocational Schools, Adıyaman, Turkey
This shows that there is no consistent trend; rather, it depends on species of plant and from one type of habitat to another.[16] reported that large propagules of Gmelina arboreaRoxb. had more rapid growth at the initial stage than small propagules due to their greater contentsfood and nutrient reserve. They also noted that although smaller propagules may although initially exhibits delayed growth, their seedlings eventually become comparable to those from larger propagules. They further stated that the initial slow growth rate of seedlings from the smaller propagules was due to the intrinsic nutrient resource pool of the seeds. After this stage, growth establishment is shifted to the extrinsic nutrient resource pool available in the immediate environment of the seedlings [16].

T. occidentalis Hook F. (Fluted pumpkin) is one of the various vegetables consumed by many households. It is a tropical crop belonging to the family Cucurbitaceae [25]. It is believed to have originated in West Africa's rainforest belt [17]. Telfairia occidentalis is widely consumed in tropical regions. The crop is grown across the lowland humid tropics. The major producing countries of the crop are Nigeria, Ghana and Sierra Leone. The plant is dioecious, perennial and drought tolerant. In Nigeria, we have two main cultivars which are "Ugu-ala" and "Ugu-elu" [20]. The "Ugu-ala" is characterized by succulent, broad leaves, small black seeds, thick stem and slow growth. The "Ugu-elu" has a high growth rate, large brownish seeds with high viability, and thin stem with small leaves. The large succulent leaves of "Ugu-ala" make this cultivar a commercial vegetable in high demand, while the fast emergence and high growth rate of "Ugu-elu" is preferred by farmers because of quick returns. In this study, "Ugu-elu" is used to determine the effect of seed size and sowing depths on the growth of seedlings of $T$. occidentalis. The ecological and silvicultural significance of variations in seed size of the species are examined.

\section{MATERIALS AND MethodS}

Certified fruits of $T$. occidentalis were collected from National Root Crops Research Institute (NRCRI), Umudike, Abia State, Nigeria. The seeds were harvested from one single fruits to ensure accurate results. Three seed sizes, namely: small seeds $(10.01-10.05 \mathrm{~g})$, medium seeds $(22.25-22.30 \mathrm{~g})$, large seeds $(32.25-33.00 \mathrm{~g})$, were used for the study. The weights of the seeds were used as measure of their sizes. The field was cleared of weeds and plowed. Beds of $4 \mathrm{~m} \times 9 \mathrm{~m}$ were made. Three seeds of $T$. occidentalis per hole were planted at four different soil depths: $3 \mathrm{~cm}, 6 \mathrm{~cm}, 9 \mathrm{~cm}$ and $12 \mathrm{~cm}$ 
in a spacing distance of $40 \mathrm{~cm}$ between plants and $80 \mathrm{~cm}$ between rows to give a total of 640 plants/plot. From 6 days after planting of seeds, the resulting seedlings were later thinned down at two leaf stage to one plant per stand. This was to obtain uniform growth vigour and density of the plant. Beds received $320 \mathrm{~g}$ of NPK fertilizer (12:12:17), in order to ensure optimum crop yield. The fertilizer was added to the soil before planting to ensure that the plants did not suffer from or experience nutrient deficiency. Weeds were removed at weekly intervals and the experiment lasted for a period of four months (May to August 2008).

A split plot experiment in a randomized complete block design (RCBD) with four replications was used in this study. Four sowing depths constituted the main-plots and three seed sizes as the sub-plots. The treatments were replicated four times to give a total of 48 experimental units. The total experimental area was $1000 \mathrm{~m}^{2}$, consisting of 4 beds, each sub-divided into 4 sub-blocks. Three seeds were planted per hole which was later thinned down to one seed per stand giving a total of 144 seeds. Data obtained were statistically analysed using the GenStat statistical software and the treatment means separated using Fisher'-Least significant difference according to the procedures of [23] and [1].

\section{DISCUSSION OF RESULTS}

\section{A. Germination and Emergence}

In this experiment, small seeds germinated faster and are more established than the medium and large seeds. This is in line with the reports of [12] in wheat cultivars and [18] in rice. These researchers stated that large seeds have slower germination rates than small seeds. [6] also noted that plants established from small-seeds soybean varieties (Glycine max L. Merr.) yielded more leaves and shoots than those established from large-seeded varieties.

The interactions between sowing depths and the seed sizes in this study have shown that small seeds planted deeper $(9 \mathrm{~cm}$ and $12 \mathrm{~cm}$ ) germinated faster when compared with $3 \mathrm{~cm}$ and $6 \mathrm{~cm}$ sowing depths. This finding is in line with [21] reported in Spring Cabbage. The researchers noted that seeds sown $5 \mathrm{~mm}$ deep emerged 10.1 days after seeding. This may be attributed to the fact that there is availability of more moisture in the soil at deeper $(12 \mathrm{~cm})$ than the shallower sowing depth $(3 \mathrm{~cm})$. Similar results were also obtained by [7]. The medium and large seeds, irrespective of the sowing depths, germinated 16 to 24 days and 24-43 days after planting respectively.

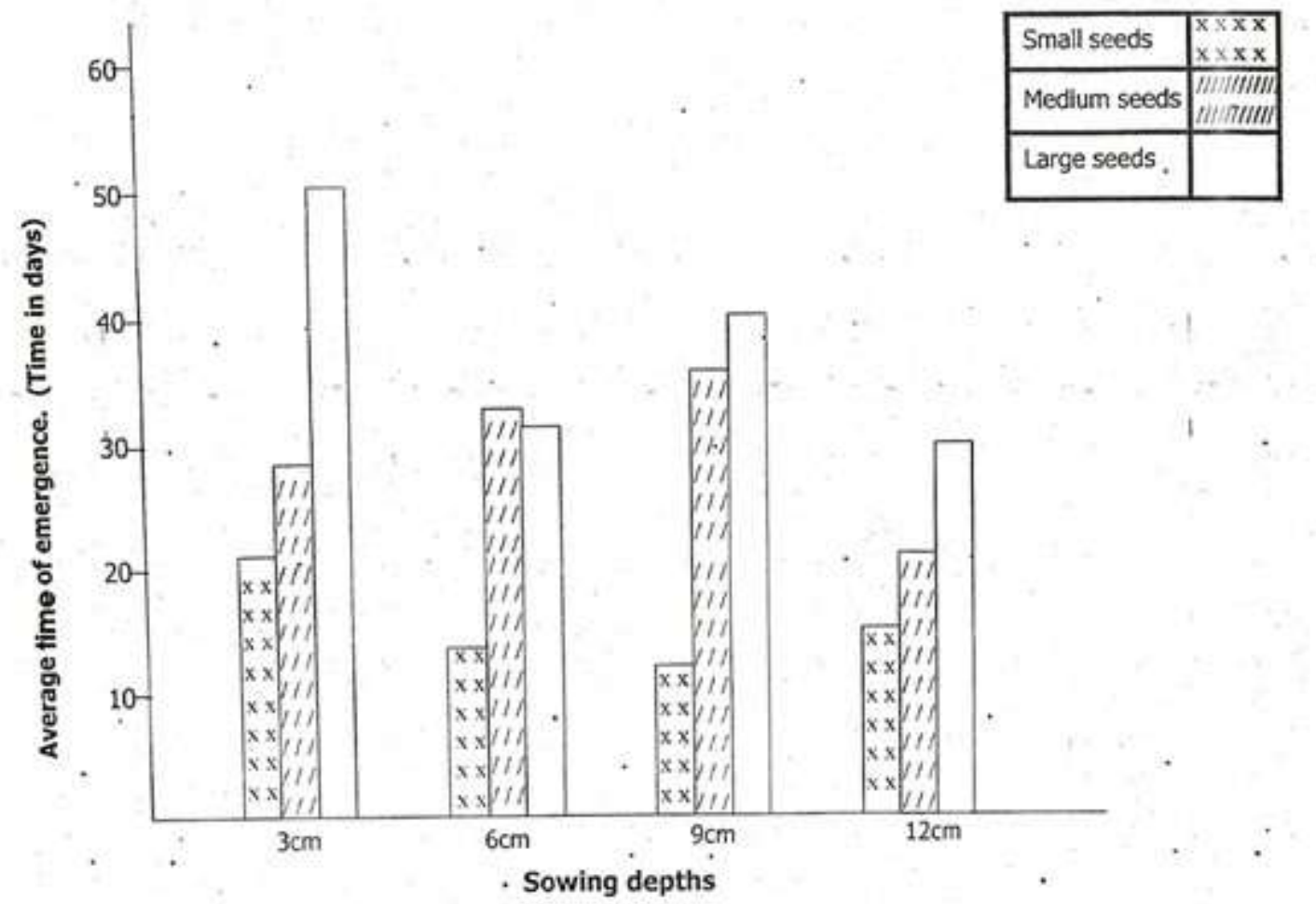

Fig.3.1: Effects of four different sowing depths $(3,6,9,12 \mathrm{~cm})$ on emergence of three varying seed sizes of T. occidentalis grown in the field. 


\section{B. Growth}

The study revealed that increasing sowing depths significantly reduced cumulative height growth over time. This trend is in line with what [26] noted in growth chambers studies of Brassica rapa. [10] demonstrated that in an open habitat, plants with small propagules increased their weight more rapidly than those with large propagules, while in a closed habitat, those with large propagules did so more rapidly. During the growth period, small seeds attained the highest plant height irrespective of the sowing depth.

Root lengths generally were not affected by the sowing depth; but were affected by the sizes. Small and medium seeds recorded higher root length when compared with those of large seeds. This contradicts what [22], [2], [3] and [19] reported. They suggested that a large seed enables a seedling to allocate proportionally more resources to root development than dose a smaller seed.

Sowing depths, seed sizes and, interaction between sowing depths and seed sizes had significant effect on the collar diameter. Small seeds had the highest radial growth from the beginning to the end of the growth period, followed by the medium.

The study revealed that sowing depths and seed sizes had significant effect on leaf area and leaf number. There were significant differences on the leaf area as influenced by the seed sizes when compared with the control (small seeds) at the $6^{\text {th }}$ and $8^{\text {th }}$ [weeks of harvest. This trend agrees with what [15] reported. They stated that seed size affects vigour, germination and seedling establishment. Small seed had greater number of leaves. It is generally known that seedling depth and seed size are the major factors influencing seedling emergence, stand establishment, and crop performance [13]. Smaller seeds, however, may gain an advantage over large seeds by germinating faster [24]. Large seeds attained the highest leaf area ratio when compared with the small and medium seeds from the beginning to the end of the experiment, irrespective of the sowing depths. This finding is in line with those of [27] and [4] who reported that large seeds produce large seedlings.

The performance of any plant in terms of dry matter production is directly dependent on the pattern of its leaf area development in response to solar energy and carbon dioxide perception. The study revealed significant differences among the sowing depths. There were significant differences on seed sizes; small seed had the highest value of dry matter production. This is in agreement with the findings of [24] and [8].

From the study it was observed that $12 \mathrm{~cm}$ attained the highest root-shoot ratio. In other words, the plant attained more roots at the deeper end than at the shallow end. Large seeds had the highest root-shoot ratios. Large seeds enable seedlings to allocate proportionally more resources to root development than small seeds [22]; 2]; [19]; [14].

It was observed that $12 \mathrm{~cm}$ had the greatest relative growth rate of $3.98 \mathrm{~g}$. The least was $3 \mathrm{~cm}$, having relative growth of $2.52 \mathrm{~g}$. This finding is in line with what [5] observed on the effects of planting depths on four Loves grasses. They noted that deep seed placement minimizes water stress expressed by emerging seedlings. Small seeds had the highest relative growth rate of $4.62 \mathrm{~g}$ while the least was the large seeds with relative growth rate of $2.28 \mathrm{~g}$. This finding agrees with what [24] and [8] observed in Alliariapetiolata and Pastinaca sativa L. respectively.

\section{CONCLUSION}

Assessment of the effects of seed size and sowing depths on emergence and seedling development of Telfairia occidentalis shows that small seeds germinates, and establish faster than medium and large seed sizes. Small seeds also grow and develop irrespective of the sowing depths. This feature suggests that smaller seed is the best seed size suitable for farmers who cultivate $T$. occidentalis for commercial purposes. Its rate of germination and establishment yields more stem and leaf. The study has also shown that small seeds can do very well in any sowing depths. Medium and large seeds take some time to germinate and establish. However over time, they perform very well, and sometimes better than small seed sizes.

\section{REFERENCES}

[1] Alika, J. E. (2006). Statistical and Research Methods. $2^{\text {nd }}$ Edition.Ambix Press, Benin City, Nigeria. Viii + 366pp.

[2] Baker, H. B. (1972). Seed weight in relation to environmental conditions in California. Ecology, 53:997-1010.

http://dx.doi.org/10.2307/1935413

[3] Bernard, R. B. and Toft, A. C. (2007). Effect of seed size on seedling performance in a long-lived Desert perennial shrub (Ericamerianauseosa: Asteraceae). Int. J. Plant Sci., 168(7): 10271033. http://dx.doi.org/10.1086/518942

[4] Bower, J. E., Turner, R. M., Burgess, T. L. (2004). Temporal and spatial patterns in emergence and early survival of perennial plants in the Sonoran Desert plant.Ecol, 172:107-119. http://dx.doi.org/10.1023/B:VEGE.0000026026.34760.1b

[5] Cox, J. R., and Martin, M. H. (1984). Effects of planting depths and soil textures on the emergence of four loves grasses. J. Range Mgmt., 37:204-205. http://dx.doi.org/10.2307/3899137

[6] Dhillon, G. S. and Kler, D. S. (1976).Crop production in relation to seed size.SeedRes., 4:143-155.

[7] Gan, Y. T., Miller, P. R. and McDonald, C. L. (2003). Response of Kabulia chickpea to seed size and planting depth. Semiarid Prairie Agricultural Research Centre. Can. J. Plant Sci., vol 83:39-46. http://dx.doi.org/10.4141/P02-064

[8] Hendrix, S. D., Nielsen, E. T., Schutt, M. (1991). Are seedlings from small seedsalways inferior to seedlings from large seeds? Effects of seed biomass on seedling growth in Pastinaca Sativa L. New Phytol., 119:299-305 http://dx.doi.org/10.1111/j.1469-8137.1991.tb01034.x

[9] Hoffman, I. C. (1925). The relation of size of Kernels in sweet corn evenness of maturity. Journ. Agric. Res., 31: 1043-1053.

[10] Kondo, Y. and Oshima, Y. (1981). Propagule size and growth of plant phenomenon of gaining in growth by plant handicapped by small initial size. Jap. J. Ecol., 31: 217-219.

[11] Korstian, C. (1927). Factors controlling germination and early survival in oaks.YaleUniv. School of Forest. Bull., 19:7-115.

[12] Lafond, G. P. and Baker, R. J. (1986)a. Effects of temperature, moisture stress, and seed size on germination of nine spring wheat cultivars. Crop Sci., 26:563-567. http://dx.doi.org/10.2135/cropsci1986.0011183X002600030028x

[13] Lamb, K. E. and Johnson, B. L. (2004). Seed size and seedling depth influence on canola emergence and performance in the Northern Great Plains. Agron. J. 96: 454-461. 
http://dx.doi.org/10.2134/agronj2004.0454

[14] Leishman, M. R. and Westoby, M. (1994). Hypotheses on seed size: Tests using the semiarid flora of Western New South Wales, Australia. Am/Nat.., 143: 890-906.

http://dx.doi.org/10.1086/285638

[15] Leishman, M. R., Wright, I. J., Moles, A. T. and Westoby, M. (2000). Evolutionary ecology of seed size, pp. 31-57, In: M. Fenner (ed) Seeds. The ecology and regeneration in plant communities. $2^{\text {nd }}$ ed. CAB Int. New York. http://dx.doi.org/10.1079/9780851994321.0031

[16] Ogbonnaya, C. I. and Kinako, P. D. S. (1990).Propagule size and seedling growth relationships in GmelinaarboreaRoxb. Discovery and Innovation, 2: 5 .

[17] Okoli, B. E. and Mgbeogu, C. N. (1983). Fluted pumpkin (T. occidentalis): A. West African vegetable crop.New York Botanical Garden Brons. Vol. 37:12-14. http://dx.doi.org/10.1079/9780851994321.0031

[18] Roy, S. K. S., Hamid, A., Gia, S. M. M. and Hashem, A. (1996). Seed size variation and its effects on germination and seedling vigor in rice. J. Agron. Crop.Sci., 176: 79-82. http://dx.doi.org/10.1079/9780851994321.0031

[19] Salisburg, E. J. (1974). Seed size and mass in relation to environment. Proc. R. Soc. B., 186: 83-88. http://dx.doi.org/10.1098/rspb.1974.0039

[20] Schippers, R. R. (2000). African Indigenuous Vegetables. An overview of the cultivated species. Chathan UK: National resources Institute/ACPEU Technical Centre for Agricultural and Rural Cooperation.

[21] Shanmugantha, V. and Benjamin, L. (1991). The influence of sowing depth and seed size on seedling emergence time and relative growth rate in spring cabbage (Brassica oleracea var. capitata L. ) An. Bot. (Lond.), 69: 273-276.

[22] Stebblies, G. L. (1971). Adaptive radiation and reproduction characteristics in angiosperms. II. Seeds and seedlings. Annu. Rev. Ecol. Syst., 2: 237-260. http://dx.doi.org/10.1146/annurev.es.02.110171.001321

[23] Steel, R. G. D. and Torrie, J. H. (1980). Principles and Procedures of Statistics: A Biometric Approach.McGraw-Hill Publications, New York. 633pp.

[24] Susko, D. J., Lovett-Doust, L. (2000). Patterns of seed mass variation and their effects on seedlings in Alliariapetiolata. Am. J. Bot., 8: 56-66. http://dx.doi.org/10.2307/2656685

[25] Taylor, O. O. A., Futuga, B. L., Oyenuga, U. A. (1983). Amino acid compositions and nutritive value of two cucurbitaceae species as affected by level of nitrogen fertilization and age at harvest. Nutrition Reports International, 28 (5): 1037 -1048.

[26] Vigil, M. F., Anderson, R. L. and Bear, W. E. (1997). Base temperature and growing -degree-house requirements for the emergence of canola. Crop Sci., 37: $844-849$. http://dx.doi.org/10.2135/cropsci1997.0011183X003700030025x

[27] Wulff, R. D. (1986). Intraspecific variation in germination requirements and growth in Amaranthusdubius. Am. J. Bot., 75: 1307-1312. http://dx.doi.org/10.2307/2444453 


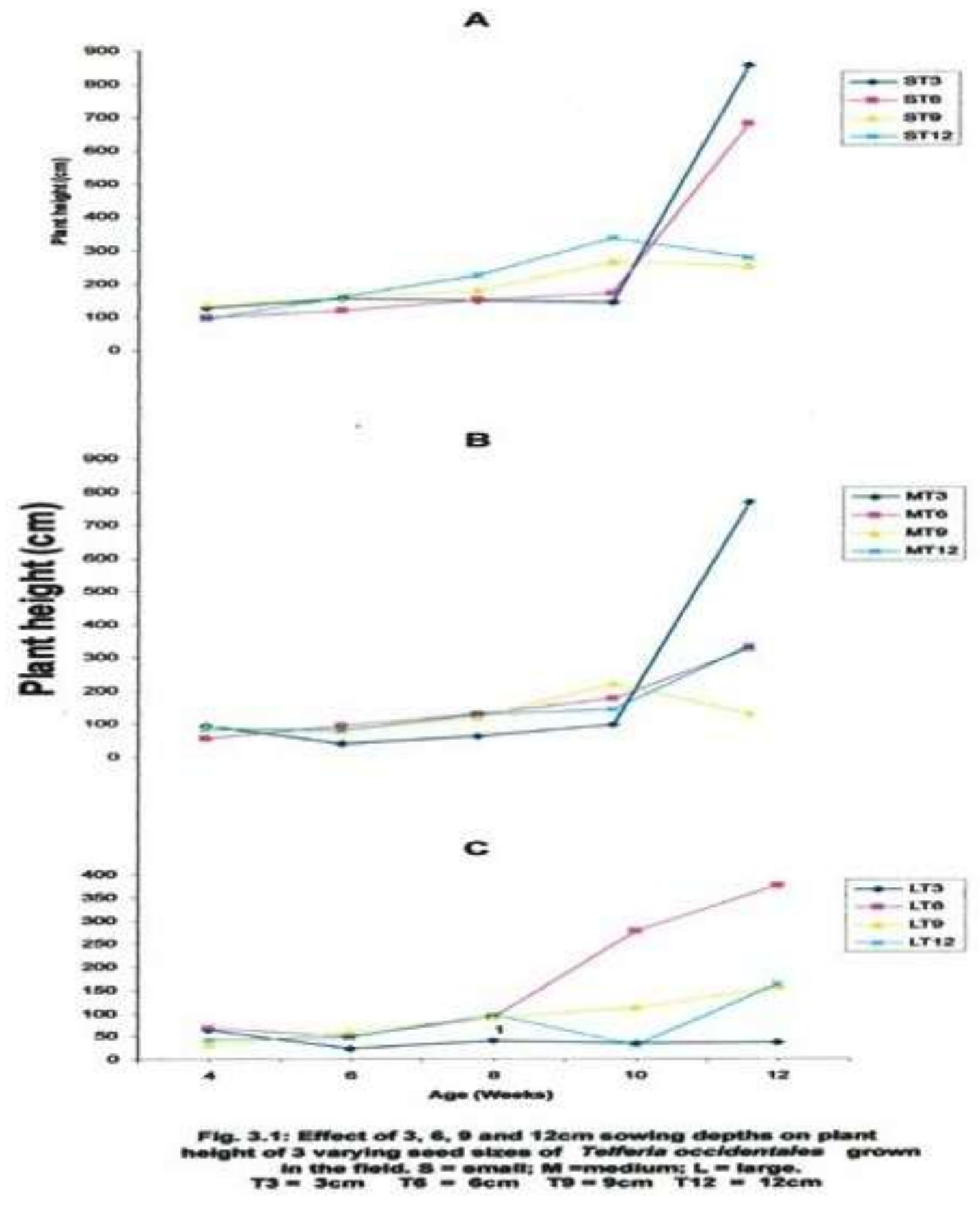




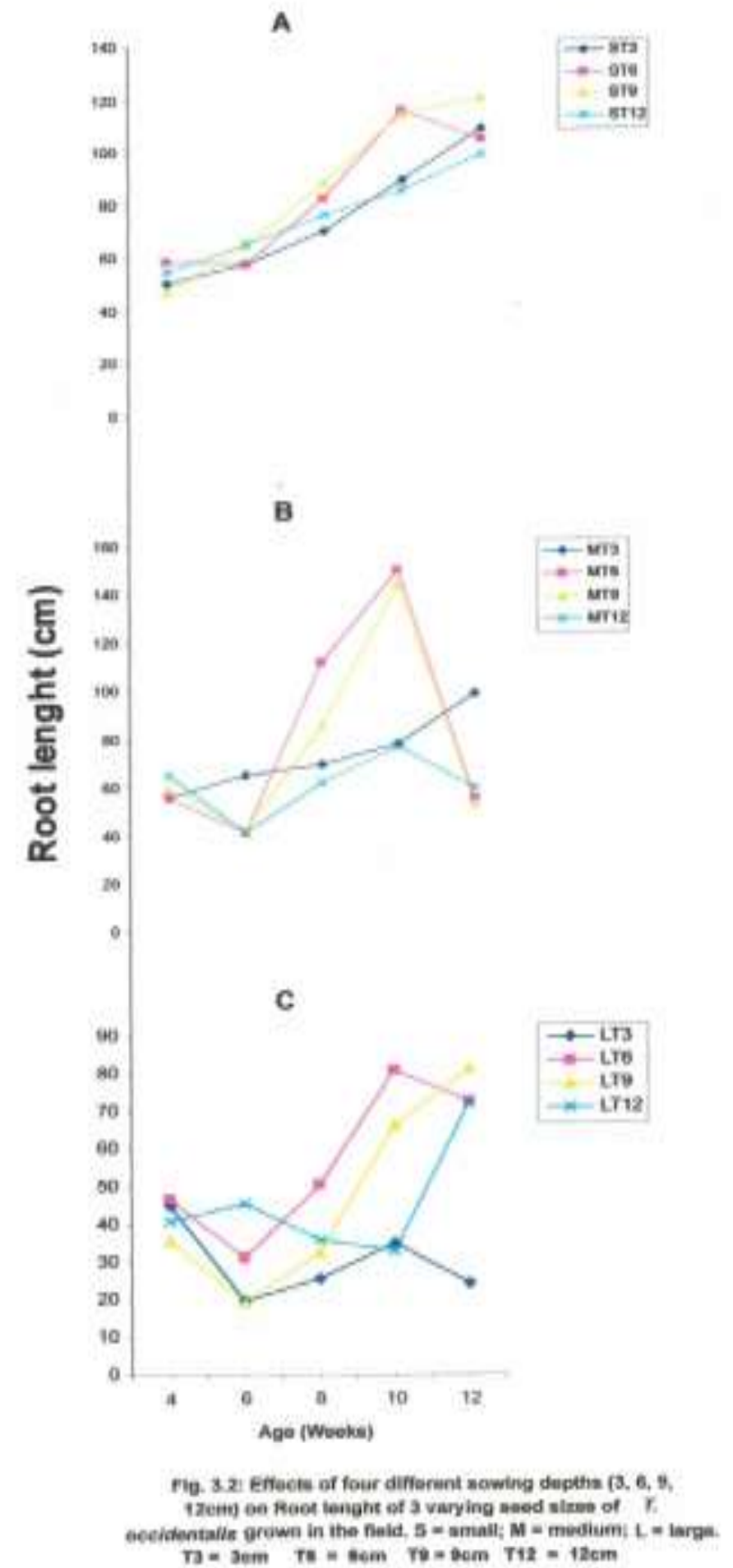




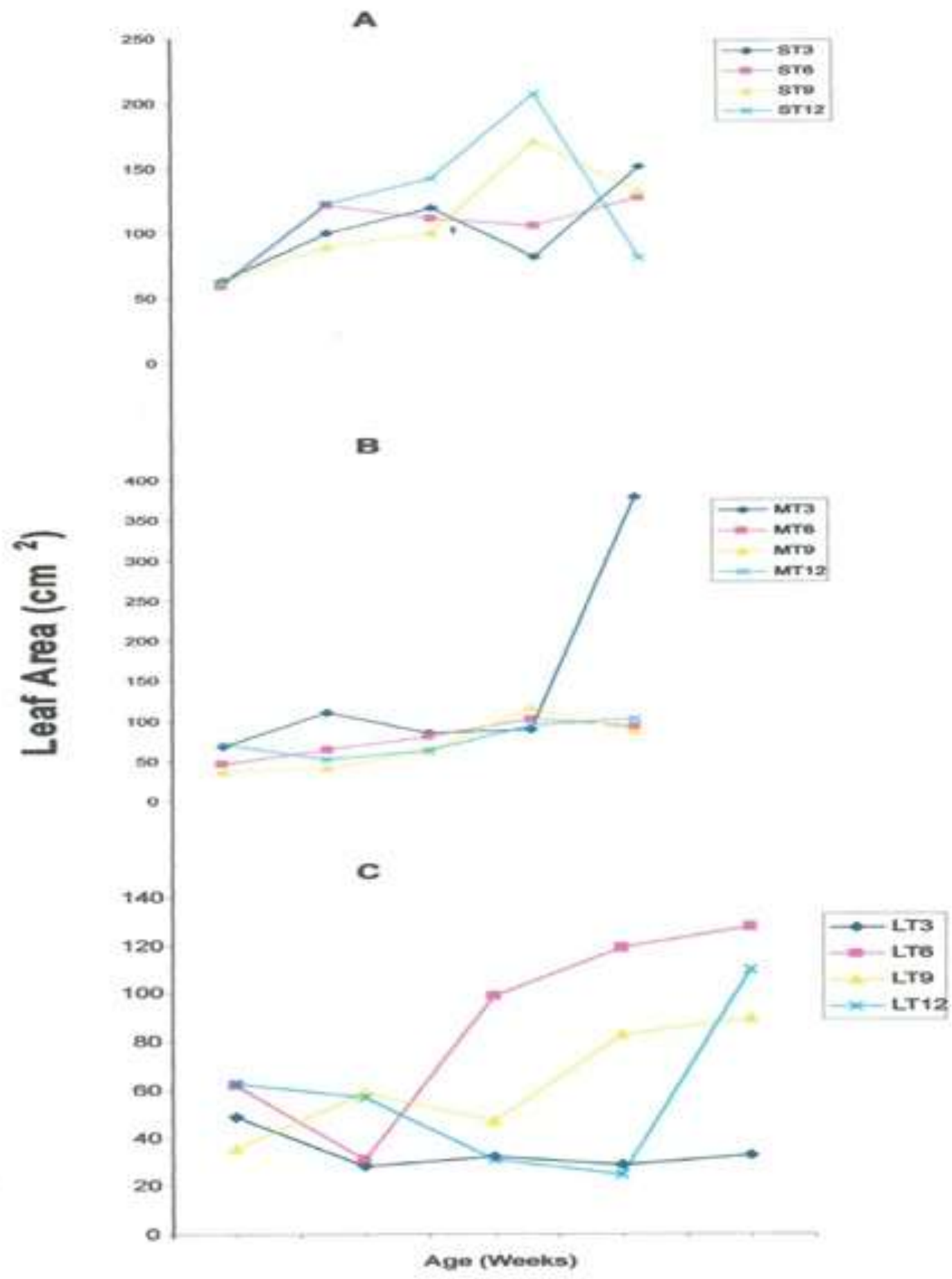

Fig. 3.3: Erfect of 3, 6, 9 arte $12 \mathrm{~cm}$ sowing depths on Leaf area of 3 varying seod sixesTobceidentalgrown in the fletd. $8=$ smait: $M=$ modium: $L=$ large.

$\mathrm{T} 3=3 \mathrm{~cm}$ TS $=6 \mathrm{~cm}$ T9 $=9 \mathrm{~cm} \quad \mathrm{c} 12=12 \mathrm{~cm}$ 